\title{
Pediatri Polikliniğinden Ortopedi Bölümüne Danışılan 0-3 Yaş Arası Ardışık 100 Hastanın Analizi
}

\author{
Analysis of Consecutive 100 Patients Aged Between 0-3 Years Who were Consulted \\ with The Orthopedics Department by Pediatrics Outpatient Clinic
}

\section{Op. Dr. Recep ÖZTÜRK ${ }^{1}$, Dr. Murat Yasin GENÇOĞLU ${ }^{2}$, Uz. Dr. Ömer Faruk ATEŞ ${ }^{3}$ Doç. Dr. Mahmut Nedim AYTEKİN ${ }^{4}$, Op. Dr. Orçun TOKTAŞ 5}

\author{
1. Polatl Devlet Hastanesi, Ortopedi ve Travmatoloji Kliniği, Ankara, Türkiye \\ 2. Dr. Sami Ulus Kadın Doğum Çocuk Sağlığı ve Hastalıkları Ĕgt. ve Arş. Hastanesi, Çocuk Hastalıkları Kliniği, Ankara, Türkiye \\ 3. Atatürk Ĕgitim ve Araştırma Hastanesi, Radyoloji Kliniği, Ankara, Türkiye \\ 4. Atatürk Eğitim ve Araştırma Hastanesi, Ortopedi ve Travmatoloji Kliniği, Ankara, Türkiye \\ 5. Dr. Sami Ulus Kadın Doğum Çocuk Să̆lığı ve Hastalıkları Ĕ̆t. ve Arş. Hast., Ort. ve Travmatoloji Kliniği, Ankara, Türkiye
}

\section{$\ddot{O Z Z E T}$}

Amaç: Bu çalıșmada, 0-3 yaş arası erken çocukluk döneminde çocuk polikliniğinden ortopedi polikliniğine danışılan hastaların demografik verilerinin analizi amaçlandı.

Gereçler ve Yöntem: 2017- 2018 yılları arasında, çocuk polikliniğinden ortopedi polikliniğine konsulte edilen hastalar içinden, 0 ile 3 yaş arası yaşları olan ardışı yüz hastanın, yaşları, klinik bulguları ve ortopedik inceleme sonuçları retrospektif olarak incelendi.

Bulgular: Yaşları 1 ay ile 36 ay arası değișen, ortalama yașları 17 ay olan 100 çocuk hastanin 54 ü klz, 46 si erkek hasta idi. 14 farklı ön tanı ile hastalar ortopedi kliniğine danışıldı. En sık danışılma nedeni gelişimsel kalça displazisi ön tanısı idi (44 hasta). Danışılan hastaların 14 ünde gelișimsel kalça displazisi saptandl. İkinci en sık ön tanı, içe basma idi (25 hasta). Diğer daha nadir ön tanılar, doğumsal klavikula kırı̆̆ (9 hasta), tortikollis (4 hasta), pes equinovarus (4 hasta), o-bone (3 hasta), eklemlerden ses gelmesi(2 hasta), eklemlerde spastisite(2 hasta), planovalgus, sellülit, parmak ucunda yürüme, sakral killanma, polidaktili, tetik parmak ve brakial pleksus hasart idi.

Sonuç: Çocuk hastalıkları kliniklerindeki 0-3 yaş arası erken çocukluk muayenelerinde en sik rastlanılan ortopedik patolojiler gelişimsel kalça displazisi ve içe basma olmakla birlikte, klinisyenin en az ondan fazla sik görülen ortopedik patoloji hakkında şüpheci olması önemlidir.

Anahtar Kelimeler: gelişimsel kalça displazisi, içe basma, erken çocukluk

\section{ABSTRACT}

Objective: In this study, we aimed to analyze demographic data of the children aged between 0 and 3 years who were consulted with the orthopedics department by pediatrics outpatient clinic.

Material and Methods: Ages, clinical findings, and radiologic examination outcomes of consecutive 100 patients who were consulted with the orthopedics department by pediatrics outpatient clinic between 2017 and 2018 were retrospectively studied.

\section{İletişim}

Sorumlu Yazar: Op. Dr. Recep ÖZTÜRK

Adres: Polatlı Devlet Hastanesi, Karapınar Mahallesi, Eskişehir Yolu Üzeri Abdülaziz Cad. No:2, 06900 Polatlı, Ankara, Türkiye

Tel: +90 (505) 4634794

E-Posta: ozturk_recep@windowslive.com

Makale Geliş: 06.01.2018

Makale Kabul: 02.04.2019

DOI: http://dx.doi.org/10.16948/zktipb.429353
Results: Of the 100 pediatric patients aged between 1 month and 36 months witha mean age of 17 months, 54 were girls and 46 were boys. Orthopedics clinic was consulted with 14 different presumed diagnoses. The most common cause of consultation was the presumed diagnosis of developmental hip dysplasia (44 patients). Developmental hip dysplasia was detected in 14 of the consulted children. The second most common presumed was in-toeing (25 patients). The other less frequent presumed diagnoses included congenital clavicular fracture $(9$ patients), torticollis (4 patients), pes equinovarus deformity (4 patients), o-bone (3 patients), noisy joints (2 patients), articular spasticity (2 patients), planovalgus, cellulitis, toe walking, sacral hirsutism, polydactylism, trigger finger, abd brachial plexus damage.

Conclusion: The most common orthopedic pathologies in the early childhood examination of pediatric patients aged between 0 and 3 years in pediatric clinic are developmental hip dysplasia and in-toeing, although clinicians should suspected of at least more than ten common orthopedic pathologies.

Keywords: developmental hip dysplasia, in-toeing, early childhood

\section{GİRIŞ}

1741 y1lında, Paris Üniversitesinden Profesör doktor Nicholas Andry, düzgün ve çocuk anlamlar1na gelen orthos ve paidios kelimelerini birleştirerek ortopedi terimini tanımlamıştır (1). Ancak ne yazık ki, kas-iskelet bakımı ile ilgili bilgi ve konfor, çocuk doktorları tarafindan tüm ileri uzmanlık sistemlerinin en düşük seviyesini tarihsel olarak sıralamaktadir (2).

Çocuklar büyüklerin küçültülmüş hali değildir. Çocuk ortopedi bu sebeple büyüklerin ortopedik sorunlarından önemli farklılıklar gösterir. Pediatrik ortopedide, çeşitli hastalıkların, bozuklukların ve yaralanmaların etkileri en iyi şekilde, geçmiş büyüme temelinde analiz edilirken, tedaviler çoğunlukla, çocuğun gelecekteki çeşitli tipteki büyümesi ile ilgili varsayımlara dayanarak planlanır (3).

En sık görülen çocukluk çağı ortopedik hastalıkları gelişimsel kalça displazisi (GKD), pes ekinovarus, pes planus, yürüme bozuklukları, tortikollis ve $\mathrm{O}$ bacaktır $(4,5)$. Bu çalışmada, pediatri polikliniğinden 0-3 yaş arası erken çocukluk döneminde ortopedi polikliniğine danışılan hastaların demografik verilerinin analizi amaçlandı. 


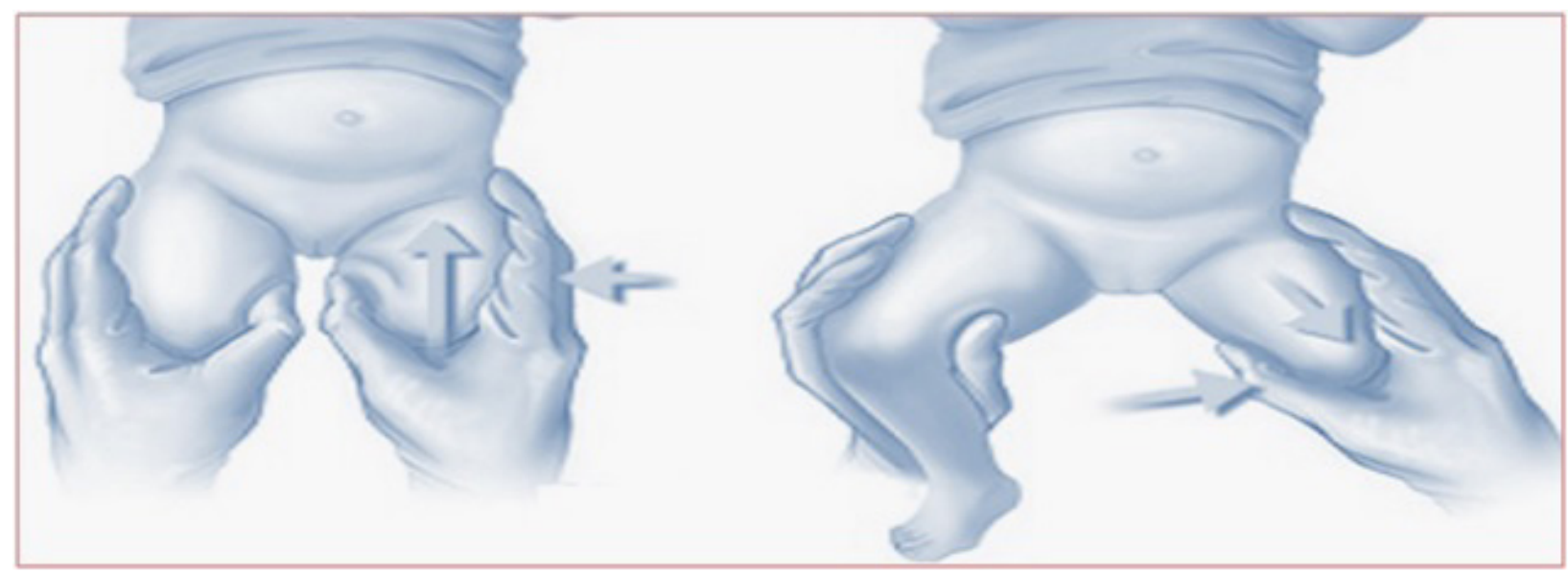

Resim 1: Gelişimsel kalça displazisi muayenesi a) barlov testi b) ortolani testi.

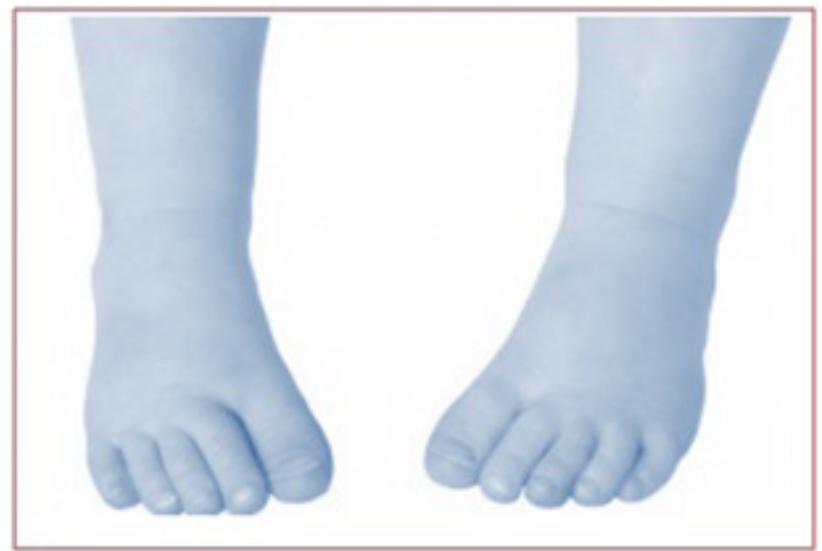

Resim 2: Çocukta içe basma. Femoral anteversiyon, tibial torsiyon ve metatarsus adductus ayrımı yapılmalidır.

\section{GEREÇ ve YÖNTEM}

2017- 2018 yılları arasında, hastanemiz çocuk hastalıkları polikliniğinden, ortopedi polikliniğine konsulte edilen hastalar içinden, yaşları 0 ile 3 yaş arası olan, ardışık yüz hastanın, yaşları, klinik bulguları ve ortopedik inceleme sonuçları retrospektif olarak incelendi.

Gelişimsel kalça displazisi açısından ortopedi polikliniğine danışılan hastalarda, danışılma kriterleri; rutin gelişimsel kalça displazisi taraması, muayenede abduksiyon kısitlılığ 1 , pili asimetrisi, risk faktörleri varlığı ya da ortoloni testi pozitif saptanan hastalar idi (Resim 1).
İçe basma açısından danışılan hastalarda içe basma tanımı, yürürken veya adım atarken ayaklarının içi göstermesi durumu olarak belirlendi (Resim 2).

Doğumu takip eden erken dönemde karşılaşlan, bebeğin omzunu hareket ettirmemesi ya da omuzda şişlik, hassasiyet bulgularında doğumsal klavikula kırığ ya da doğumsal brakial pleksus hasarı ön tanısı ile ortopedi konsultasyonu yapıdı (Re$\operatorname{sim} 3)$.

Tüm istatistiksel analizler, IBM SPSS 22.0 istatistik yazılımı (IBM Corp.,Armonk, NY, ABD) kullanılarak gerçekleştirilmiştir. Tanımlayıcı istatistikler ortalama \pm standart sapma, sıklık ve yüzde olarak ifade edildi.

\section{BULGULAR}

54'ü kız, 46'sı erkek toplam 100 hastanın yas ortalaması 17 ay (1-36 ay arası) idi. Çocuk polikliniğinden ortopedi polikliniğine en s1k danışılma nedeni, gelişimsel kalça displazisi ön tanısı idi.

Gelişimsel kalça displazisi açısından toplam 44 hasta (\%44) danışıldı. Bu hastaların $35^{\prime}$ i, sağlam çocuk muayenesi sonrası, kalça gelişim bozukluğu rutin taraması için yönlendirilen hastalar iken, 9'u, klinik muayenede kalça gelişim bozukluğu düşünülen hastalar idi.

Muayene ve kalça ultrasonu sonuçlarına göre toplam 14 hastada gelişimsel kalça displazisi saptandi.

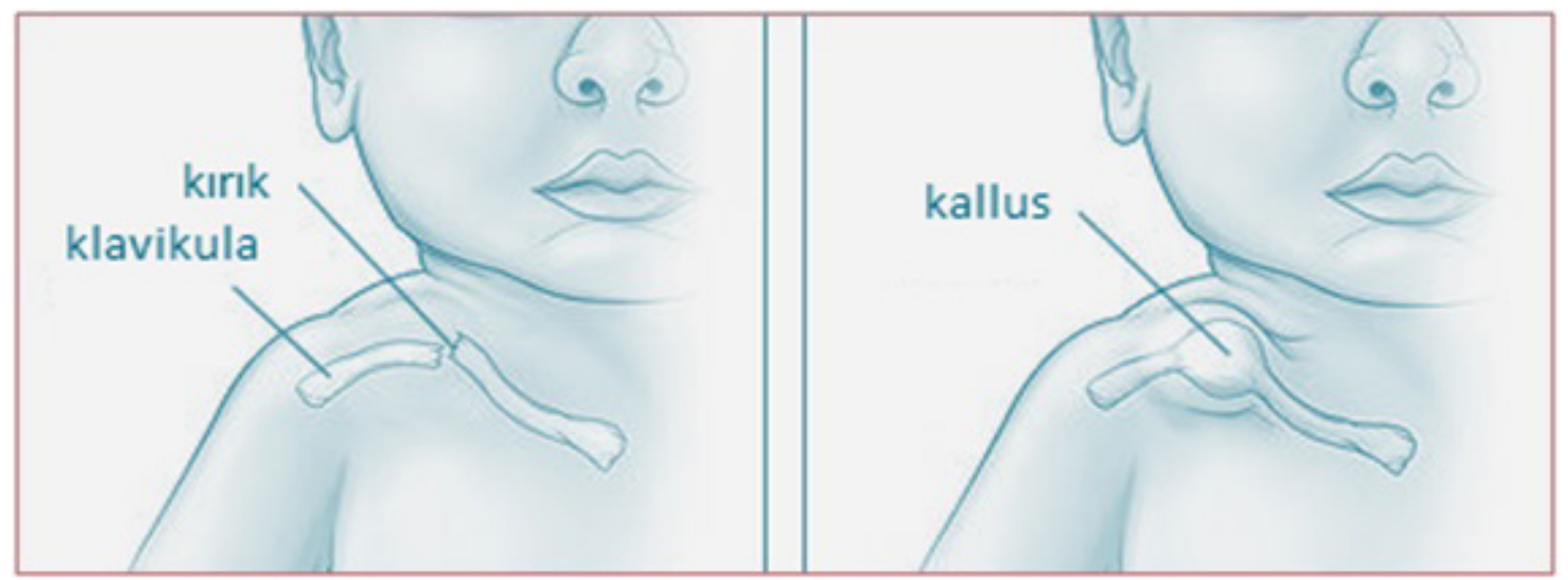

Resim 3: Obstetrik klavikula kırığı. a) klavikula kırığı b) kırık hattında oluşan kallus dokusu. 
İçe basma açısından danışılan 25 hastanın tümünde fizyolojik içe basma mevcuttu ve nedenleri femoral anteversiyon, tibial torsiyon ya da ayağın içe basması idi. Hiçbir hastada konjenitalvertikaltalus ya da tedavi gerektiren eşlik eden patolojiye saptanmadi. Tümüne takip önerildi.

9 bebekte doğum anında gelişmiş klavikula kırı̆̆1 mevcuttu ve tümü konservatif yöntemlerle tedavi edildi. 4 hastada muayene ve ultrason ile degerlendirme sonucunda tortikollis saptandi. Fizik tedavi uygulandi. 4 hastada klinik muayene ile pes equinovarus tanını konuldu. Tümüne ponseti yöntemi ile konservatif tedavi uyguland.

3 hastada o-bone saptand1. Bu hastalar ortopedik yönden izleme alındı ve ditamin d eksikliği tipinin tanımlanması ve tedavi programı açısından çocuk endokrin bölümüne yönlendirildi.

Bir hasta diz eklemlerinden ses gelmesi şikayeti ile ailesi tarafından getirildi. Yedi aylık bir erkek olan hastanın dizlerinde fleksiyon ile hafif ses mevcuttu. Muayene ve radyolojik incelemede patoloji saptanmadı takibe alındı. İki yaş bir aylık, sol kalçadan hareket ile ses gelmesi nedeniyle danışılan hastanın kalça fleksiyonu ile hafif ses mevcuttu. Muayene ve radyolojik incelemede patoloji saptanmadı takibe alındı

Eklemlerde spastisite nedenli danışılan üç yaşında hastanın diplejik serebral palsi tanısı ile, çocuk nöroloji bölümü takibine devri yapıldı. Bilateral ayak bileğini saran ayak-ayak bileği ortezi yapıldı. Sekiz aylik erkek hastanın tüm ekstremitelerinde spastisite ve gelişme geriliği mevcuttu. Çocuk nöroloji bölümüne ortezleri ve takibi, tedavisi açısından devredildi.

Her iki ayağında eğrilik bulguları ile danışılan iki buçuk yaşında hastanın bilateral planovalgusu mevcuttu. Ayak-ayak bileği ortezi yapıldı. Genel bağ gevşekliğinin bulunduğu sendromlar açısından (ehler danlos, down, marfan vb.) inceleme yapıld1. İzole esnek düztaban tanısı konuldu. Takibe alındı.

Sağ ayak dorsumunda şişlik ısı artışı ve kızarıklık nedeniyle danışılan iki yaş bir aylık hastaya sellülit tanısı ile antibiyoterapi başlandı. Semptomlar tamamen rezolve oldu. Bilateral parmak ucunda yürüme nedeniyle danışılan hastanın, geçmişte örümcek yürüteç kullandığ 1 ve ona bağlı olduğu belirlendi. Assil tendon gerginliği ya da başka ortopedik patoloji yoktu. Takibe alındi.

Sakral bölgede k1llanma ile danıșılan hasta, spinabifida açısından klinik muayene ve lombervertebra radyolojisi incelendi ancak izole sakral killanma olduğu saptandı. Takibe alındı.

Her iki el başparmakta hareket kisıtlılığı nedeniyle danışılan hastanın bilateral tetik parmak olduğu saptand1. Aileye masaj ve egzersiz programı öğretildi. Takibe alındı. İleri yaşlarda cerrahi planlanabileceği bildirildi.

Sol ayakta altı adet parmak olduğu belirlenen 2 yaş 2 aylik erkek hastanın muayene ve grafilerinde 5. Metatars-parmak polisindaktilisi olduğu belirlendi. Takibe alındi.

Doğum sonras1 sol üst ekstremitesini hareket ettirmeme bulguları ile danışılan hastanın klinik muayene ve incelemelerinde brakial pleksus hasarı saptand. Fizik tedavi programına alındı.

\section{TARTIŞMA}

Çocuklarda anatomik ve fizyolojk özellikler yaşa göre farkl11ıklar gösterir, bu nedenle çocukluk çağ1 dönemlere ayrılır. İlk bir ay yenidoğan olarak tanımlanırken, 12 aya kadar olan dönem süt çocuğu, 1-3 yaş ise süt çocuğu olarak tanımlanır (6).

Pediatri ve ortopedi denildiğinde akla ilk gelen hastalık gelişimsel kalça displazisidir. Çalışmamızda da pediatri bölümünden ortopedi bölümüne dan1ş1lan en sık hasta grubunun gelişimsel kalça displazisi ön tanılı hastalar olduğu görülmektedir.

Kalça eklemi farklılaşması intrauterin dönemin yedinci haftasında başlar. (7) Gelişimsel kalça displazisi (GKD), kalçayı oluşturan yapıların intrauterin oluşumları sırasında normal olmalarına karşın, çeşitli nedenlerle sonradan yapısal bozulma gösterdiği dinamik bir hastalıktır. Daha önceleri kullanılan Doğuştan kalça çıkığı terimi femur başının doğuştan asetabulumun dışında olması olarak tanımlanmakta idi. Ancak kalça çıkığının her zaman konjenital, yani doğumsal olarak ortaya çıkmamas1 nedeniyle "doğuştan kalça çıkı̆̆ı" yerine bugün artık "gelişimsel kalça displazisi (GKD)" terimi daha yaygın olarak kullanılmaktadır (8). Ülkemizde GKD görülme sıklığı \%1,4'dür (9).

GKD risk faktörleri; pozitif aile öyküsü, makat geliş, ilk çocuk ve kız olması, oligohidroamnios, metatarsus adduktus ve tortikolistir (8). Klinik tan1da yenidoğan döneminde Ortolani ve Barlow testleri önemlidir. Gelişimsel kalça displazisi tanısında en etkili yöntem, doğru yapılmış kalça ultrason (USG) incelemesidir (7).

Displazik kalçaların \%95 kadarı, pavlik bandaj vb basit yöntemlerle veya kendiliğinden düzelebilir $(7,10)$. Tanı ne kadar geç konursa yapılacak girişimlerin karmaşıklığı ve komplikasyon riski o kadar artarken, başarı şansı o kadar düşer. GKD tedavisinde özellikle yaşamın ilk 2-3 ayı altın dönemdir (11). Bizim çalışmamızda, yaşamın ilk 2-3 ayında tüm hastalara rutin kalça ultrasonu yapıldı, ayrıca diğer dönemlerdeki bebeklerde, klinik şüphe halinde ileri inceleme yapıldı.

Çocuklarda özellikle alt ekstremitelerin açısal ve torsiyonel görünümleri çocuğun yaşına göre normal kabul edilen minimal deformite aşamalarından geçebilir. Çocukların çoğunda erken dönemde görülebilen içe basma ve genu varum deformiteleri 7-10 yaşa kadar tedavisiz düzelebilir. Bebekler femoral anteversiyon ve bir miktar kalça fleksiyonu ile doğar ve doğumda yaklaşı 30 derece olan femoral anteversiyon 10 yaşında 21 dereceye düşer (12). Çocukların ortopedistlere en sik getirilme sebeplerinden biri içe basmadır. Çocuklar, femoral içe rotasyon, tibiyal mediyal torsiyon ve metatarsus adduktus sebebiyle bacaklarını içe çevirirler. Kalça rotasyonu, tibial torsiyon ve adduktus fizik muayene ile ölçülebilirken, kesin açısal değerler bilgisayarlı tomografi ile ölçülür. Femoral anteversiyon ve tibial torsiyon çocuklard zaman içinde düzelmektedir (13). Metatarsus adductusta tanı klinik olarak konulmakla beraber, tedavi konservatiftir. Çok nadiren manuplatif yöntemlerden faydagörmeyen rigit ayaklarda cerrahi gerekebilir (14). Bizim çalışmamızda tüm içe basma vakalarında konservatif tedavi ile başarı elde edildi. 
Klavikula çocuklarda en sık kırılan kemiklerden biridir, doğımda omuzların sıkışmasına bağlı olarak indirek veya direk travmaya bağlı görülebilir. Normal doğumların \% 0,5 inde, makat gelişlerin \%1,6'sında, 4000 gramdan büyük çocukların \%13ünde görülür. Bazen kallus dokusuna bağlı şişlik oluşana kadar fark edilmeyebilir. önemli oranda ağrısı olan bebeklerde kol 7-14 gün sabitlenir (15). Yenidoğanda görülen klavikula kırıkları minimal tedaviyle ya da tedavisiz iyileşir. Bizim çalışmamızda 9 hastada sorunsuz iyileşme gözlendi.

Boynun ve başın bir yana, çenenin diğer yana eğik durması konjenital muskuer tortikollis (KMT) olarak tanımlanır. Sternokleidomastoid kası içinde fuziform bir şişlik-sertlik olması ve buna bağlı bebeğin başının etkilenen kas tarafına, yüzün ise ters yöne dönmesi ile kendini gösterir.Kmt erken tanıs1 için tüm yenidoğanlarda rutin baş boyun muayenesi önerilmektedir (16). Sternokleidomastoid kas içi bir şişlik saptanabilir. Üst ekstremite klinik ve nörolojik muayenesi yapılarak, inflamatuar olaylar, servikal vertebra patolojileri, nörolojik hastaliklar (klippel feil-sendromu, plagiosefali) gibi olası patolojiler ekarte edildikten sonra tani konulur (17). Kesin tanı ultrasonografi ile konur (16). Tedavi gözlem, pasif manuel germe egzersizleri, aktif pozisyonlama, sebat eden vakalarda cerrahi müdahaleyi içermektedir. Çalışmamızda kmt tanısı konulan 4 hastaya egzersiz ve pozisyonlama tedavileri uygulandi.

Tortikollis de \%20 oranında GKD ile beraber görülür. Hastaların GKD yönünden incelenmesi gerekir. Bizim çalışmamızda hiçbir hastamızda birliktelik saptanmadi.

Pes ekino varus (PEV) hastalığnda ayak tabanları birbirine, ayak sırtı diş tarafa bakar. Son yıllarda Dr. Ponseti'nin geliştirdiği, "manipülasyon" ve alçılama ile ayağın yeniden şekillendirilmesi yöntemi tüm dünyada hızla yaygınlaşmaktadır. (18) Pes ekino varus olgularını Ponseti yöntemi ile \%95'e varan bir başarıyla tedavi etmek mümkün olabilmektedir. Yenidoğan döneminde alç1lama ile ortalama 5-6 haftada tam düzelme sağlanabilmektedir. Çalışmamızda pev tanısı konulan 4 vakada seri alçılama tedavisi uygulandi.

Çocukların dizinde, 2 yaş altında 10-15 derece varus açılanması varken, 3 yaş civarında 10 derece valgus açılanması görülür. Bu valgus açılanması yedi yaş civarında ise 5-7 dereceye düşer (5). Her iki diz arasındaki uzaklığın $6 \mathrm{~cm}$ 'den fazla olması, O-bacak olarak adlandırılır (4).

Dizde varus saptandıktan sonra, ayırıcı tanıya gidilmelidir. En sık neden olan fizyolojik genu varumda, hem femur hem tibiada varus mevcuttur ve eğrilik distal femur ve proksimal tibiada artar. Fizyolojik o-bacakta, ilerleyen dönemde kendiliğinden düzelme eğilimi mevcuttur. Proksimal tibia metafizinde keskin açılanma, blount hastalığını düşündürür. Tedavide erken dönemde düzeltici ortezlerden faydalanılır. D vitamini eksikliğine bağlı raşitizmde, epifizlerde genişlemeler görülür. Ayrıca distal femur ya da proksimal tibia medial epifiz hastalığ 1 yapabilecek olan travma, enfeksiyon,displazi ya da tümör açısından ayırıcı tanıya gidilmelidir (5). Bu çalışmada o-bone saptanan üç hastada da d vitamini eksikliği saptandı ve raşitizm dışı tanıları düşündürebilecek ilave patolojiye rastlanmadi.

Serebral palsi (SP) tanımı, gelişmekte olan beyin dokusunda meydana gelen, progresyon göstermeyen bir hasar sonucu, postür ve hareketin gelişiminde progresyon gösteren ve aktivite sınırlamasına neden olan kalıc bir grup hastalığ (19). Serebral palsi tanısından şüphe edilen hastanın ilk olarak anamnezinde prenatal, perinatal ve postnatal dönemlerinde hastanın beyin fonksiyonlarını etkileyecek risk faktörleri detaylı olarak sorgulanmalıdır, sonrasında tam bir nörolojik muayenesi yapılmalıdır. Genellikle hayatın ilk iki yılında tanı konulur. Spastik ekstremiteler için klinik yaklaşım öncelikle cerrahi dışı yöntemlerdir. Fizik tedavi, breys/ortezler ve botulinum toksini gibi medikal tedavileri mevcuttur (20). Bizim çalışmamızda serebral palsili hastalara ortez tedavisi ve fizik tedavisi programı uygulandi.

Pes planovalgus, esnek düztabanlık olarak da bilinir ve yürüme esnasında ayağın loguditunal arkında azalma ve ayak arkası valgusu olarak tanımlanır. Yük verilmeyen pozisyonda, başparmağın dorsifleksiyonu ile ayak arkının oluşması, rigit düztabanlıktan ayırır. Çalışmamızda planovalgusu olan ve konservatif takip planlanan bir hasta mevcuttu (14).

Spina bifidalı çocuklar çok merkezli bir ekip izlemine gereksinim duyarlar. Amaç, mümkün olan en az şekil bozukluğu olan, kendine güveni tam, kendi kendine yetebilen, bağımsız bir bireyin topluma kazandırılmasıdır. Bebeklerin ekstremitelerinin hareket yeteneğinin sağlanması ve korunması önemlidir.

Obstetrik brakial pleksus palsisi (OBPP), dogum sırasında brakial pleksusta gelișen hasarlanma sonras1, daha çok tek kolda görülen flask paralizidir BPP sıklıkla doğum sırasında traksiyon uygulananlarda görülmektedir (21). OBPP'yi değerlendirmede yüksek rezolüsyonlu manyetik rezonans görüntüleme en iyi tanı aracidır; noninvaziftir, radyasyon riski yoktur ve bilgisayarlı tomografiden daha detayl1 bilgi vermektedir (22). Temel tedavi yöntemi düzenli fizik tedavidir. İlk ayın sonunda yapılan fizik muayenede iyileşme görülmemişse cerrahi konsültasyon yapılmalıdır. Konservatif ve cerrahi tedavi arasında seçim yaparken hastanın hikayesi, EMG bulguları, görüntüleme yöntemleri ve fizik muayene göz önünde bulundurulmalıdır (23).

Sonuç olarak; çocuk hastalıkları kliniklerindeki 0-3 yaş arası erken çocukluk muayenelerinde en sık rastlanılan ortopedik patolojiler gelişimsel kalça displazisi ve içe basma olmakla birlikte, klinisyenin en az ondan fazla s1k görülen ortopedik patoloji hakkında şüpheci olması önemlidir.

\section{KAYNAKLAR}

1. Andry N. L'orthopédie ou l'art de prévenir et de corriger dans les enfans, les difformités du corps. Paris : Alix ; 1741.

2. Taras HL, Nader PR. Ten years of graduates evaluate a pediatric residency program. Am J Dis Child 1990;144:1102-5. doi:10.1001/archpedi.1990.02150340046021 
3. Bunch WH, Dvonch VM. Pitfalls in the assessment of skeletal immaturity: an anthropologic case study. Pediatr Orthop. 1983;3 (2):220-2.

4. Bursalı A. Çocuklarda ortopedik sorunlara güncel yaklaşımlar. Türk Ped Arş 2007; 42: 52-6.

5. Senaran H. Cocukta Ortopedik Muayene. In: Cullu E. (eds). Çocuk Ortopedisi. 1. Baskl. Ankara Baycinar Yayıncılık; 2012. p. 11-29.

6. Bundak R,Neyzi O. Büyüme. In: Neyzi O, Ertuğrul $T$ (eds). Pediatri. 3. Baskı. Istanbul Nobel Tip Kitapevleri; 2002. p. 79-99.

7. Graf R, Wilson B. Sonography of the infant hip and its therapeutic implications. Weinheim: Chapman and Hall 1995 $1-126$.

8. Ayas MS. Pediatrik Kalça. In:Tolga Atay (eds). Ortopedi ve spor yaralanmaları asistan kitabl. 1. Baskı. Ankara Derman Yayıncilık;2015. p. 393-410. Doi: 10.4328/derman.3543

9. Bayındır, Tanıs Z. Bos batın filimlerinde tesadüfen karşılaşılan doğuştan kalça çıkı̆̆l ve diğer patolojileri. Hacettepe Tip Cerrahi Bülteni 1970; 3: 220-31.

10. Fujii T. Prophylaxis programme for developmental dislocation of the hip: the Japanese experience. Kalça Çıkığın Önleme Sempozyumu. İstanbul, 1997:1-11.

11. Gelisimsel Kalça Displazisi Ulusal Erken Tanı Ve Tedavi Programı; 2013.

12. Ghanem I. Lovell and Winter's Pediatric orthopedics. 6th ed. Philedelphia: Lippincott Williams \& Wilkins; 2006.

13. Yorgancigil H, Özerdemoğlu RA. Alt ekstremite torsiyonel deformitelerinin cinsiyet ve yaşa göre dağılımlart. Acta Orthop Traumatol Turc 1998; 32: 152-4.
14. Bas EG, Aktekin CN. Ayağın doğuștan ve kazanılmıs deformiteleri. In: Çullu E. (eds). Çocuk Ortopedisi. 1. Baskl. Ankara Baycinar Yayıncılık; 2012. p. 199-241.

15. Eren A, Özkan K. Cocuklarda üst ekstremite yaralanmaları. In: Çullu E. (eds). Çocuk Ortopedisi. 1. Baskı. Ankara Baycinar Yaylncilik; 2012. p. 55-66.

16. Do TT. Congenital muscular torticollis: current concepts and review of treatment. Curr Opin Pediatr 2006;18:26-9

17. Morrissy RT, Weinstein SL. Lovell and Winter's Pediatric Orthopaedics. 6th edition. Philadelphia : Lippincott Williams and Wilkins, 2006;1: 878-89

18. Ponseti IV. Congenital clubfoot fundamentals of the treatment. Newyork: Oxford University Press Inc, 1996; 1-139.

19. Rosenbaum P, Paneth N, Leviton A, Goldstein M, Bax $M$. A report: the definition and classification of cerebral palsy. UCP Research and Educational Foundation 2006; $8-14$

20. Baysal Ö. Serebral Palsi. In:Tolga Atay (eds). Ortopedi ve spor yaralanmalarl asistan kitabl. 1. Baskl. Ankara Derman Yayıncllık;2015. p. 362-66. Doi: : 10.4328/derman. 3523

21. Evans-Jones G, Kay SP, Weindling AM, Cranny G, Ward A, Bradshaw A, et al. Congenital brachial palsy: incidence, causes, and outcome in the United Kingdom and Republic of Ireland. Arch Dis Child Fetal Neonatal Ed 2003;88:185-9

22. Birchansky S, Altman N. Imaging the brachial plexus and peripheral nerves in infants and children. Semin Pediatr Neurol 2000;7:15-25

23. Andersen J, Watt J, Olson J, Van Aerde J. Perinatal brachial plexus palsy. Paediatr Child Health 2006;11:111. 